\title{
Principais impactos nas margens do Baixo Rio Bodocongó - PB, decorrentes da irrigação com águas poluídas com esgoto ${ }^{1}$
}

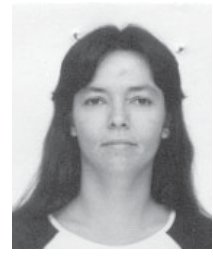

\author{
Nilana F. Magalhães ${ }^{2}$, Beatriz S. O. de Ceballos ${ }^{3}$, Ana B. de A. Nunes ${ }^{4}$, Hans R. Gheyi ${ }^{5}$ \& Annemarie Konig ${ }^{3}$ \\ 1 Parte da Dissertação de Mestrado do primeiro autor apresentada à UFPB \\ 2 Fone: (88) 423-3010. E-mail: sabourin@cirad.fr (Foto) \\ 3 DEC/CCT/UFPB. Fone: (83) 310-1154. E-mail: ceballos@cgnet.com.br e akonig@dec.ufpb.br \\ 4 Fone: (88) 423-3010. E-mail: barbararaujo@hotmail.com \\ 5 DEAg/CCT/UFPB. Fone: (83) 310-1056. E-mail: hans@deag.ufpb.br
}

Protocolo $080-1 / 6 / 2001$

\begin{abstract}
Resumo: A bacia do Rio Bodocongó se situa na região Sudoeste do Estado da Paraíba e é contribuinte da bacia do Médio Rio Paraíba, receptor da maior parte dos esgotos brutos e do efluente final da Estação de Tratamento de Esgotos (ETE) da cidade de Campina Grande. O trecho situado à jusante da ETE, aqui chamado Baixo Bodocongó, tem $50 \mathrm{~km}$ de extensão e suas águas são usadas para irrigação irrestrita, destacando-se forrageiras e hortaliças (alface, repolho, tomates) e para recreação de contato primário, dentre outros. Neste trabalho analisaram-se parâmetros sanitários, físicos e químicos de suas águas, os impactos causados pelo uso na qualidade sanitária de duas culturas irrigadas (capim e repolho) e na salinização dos solos. Verificou-se que essas águas são impróprias para irrigação irrestrita e que em nenhum dos pontos amostrados sua qualidade atende simultaneamente aos dois critérios da OMS para irrigação: coliformes fecais < 1000 UFC $100 \mathrm{~mL}^{-1}$ e ovos de helmintos < 1 ovo $\mathrm{L}^{-1}$. Os repolhos irrigados com a água desse rio apresentaram concentrações de coliformes fecais de $10^{3} \mathrm{NMP} \mathrm{g}^{-1}, 17$ vezes superior ao máximo para alimentos ingeridos crus. Essas águas têm condutividade elétrica entre 2,42 a 3,51 dS m m $^{-1}$ e as áreas irrigadas apresentam maior nível de sais em relação aos solos de áreas não irrigadas próximas.
\end{abstract}

Palavras-chave: poluição, contaminação, irrigação, salinização

\section{Principal impacts of irrigation with polluted sewerage waters on the banks of Lower Bodocongó - PB, Brazil}

\begin{abstract}
The lower basin of Bodocongó River is located in the Southwest region of the State of Paraíba and is part of watershed of Paraíba River. The river receives several diffuse sewage contributions and the final effluent of the Wastewater Treatment Plant (WTP) of Campina Grande city. The distance between the WTP and the river end, here called as Lower Bodocongó, has about $50 \mathrm{~km}$ of extension and its water is used for unrestricted irrigation of forage and vegetables (lettuce, cabbage, tomatoes), and for recreation (primary contact) purposes among others. In the present study an evaluation is made of the physical, chemical and sanitary parameters of water and the impacts of its use on the sanitary quality of the irrigated crops (elephant grass and cabbage) and soil salinization. The water of the Lower Bodocongó was found to be inappropriate for unrestricted irrigation. At none of the points sampled, water conformed simultaneously to two standards recommended by WHO for unrestricted irrigation: fecal coliforms $<1000 \mathrm{CFU} 100 \mathrm{~mL}^{-1}$ and helmints eggs $<1$ egg L-1. The cabbage irrigated with water presented a concentration of $1000 \mathrm{MPN} \mathrm{g}^{-1}, 17$ times higher than the maximum allowed by the Brazilian legislation for the raw consumption. These waters present electrical conductivity varying from 2.42 to $3.51 \mathrm{dS} \mathrm{m}^{-1}$ and salt content irrigated soils was higher than that of adjacent non-irrigated soils.
\end{abstract}

Key words: pollution, contamination, irrigation, salinization

\section{INTRODUÇÃO}

A nível global, os recursos hídricos superficiais e subterrâneos deterioram-se rapidamente, devido às múltiplas atividades que se desenvolvem de forma intensiva nas bacias hidrográficas, alterando tanto a quantidade como a qualidade da água (Tundisi, 1999). A redução da disponibilidade de recursos hídricos de boa qualidade e o aumento da produção de despejos domésticos e industriais, têm impulsionado o uso de águas de qualidade inferior na irrigação, cuja avaliação se torna necessária (Ayers \& Westcot, 1991).

A região semi-árida do Nordeste do Brasil, com cerca de um milhão de quilômetros quadrados, possui recursos hídricos superficiais escassos e mal distribuídos a nível espacial e 
temporal o que, em junção com a irregularidade das precipitações, tem provocado períodos dramáticos de seca para a população nordestina. Aliado a esse condicionante climático, o uso indiscriminado dos escassos recursos hídricos vem contribuindo de forma intensa para a degradação da qualidade da água, ampliando os problemas ambientais da região.

O Rio Bodocongó atravessa a zona semi-árida do Estado da Paraíba, passando pelos municípios de Puxinanã, Campina Grande, Queimadas e Caturité, até desembocar no Rio Paraíba, em Barra de Santana. Ao atravessar a cidade de Campina Grande, recebe lançamentos de resíduos líquidos e sólidos. A cidade possuía, em 1995, 327.000 habitantes, caracterizando-se por ter apresentado um aumento de $81 \%$ de sua população urbana no período 1970-1991 (PMCG, 1995) e, conseqüentemente, crescimento da demanda de água e produção de dejetos, não acompanhados pela implantação da infra-estrutura necessária. Desta forma, os efluentes da Estação de Tratamento de Esgotos (ETE) da cidade $\left(350 \mathrm{~L} \mathrm{~s}^{-1}\right.$ de esgotos quase "in natura" devido ao mal funcionamento da ETE) são lançados diretamente no rio e, em conseqüência, o trecho situado à jusante, aqui chamado Baixo Rio Bodocongó, encontra-se bastante poluído. Nos períodos de estiagem, os esgotos de Campina Grande chegam a representar a quase totalidade da sua vazão. Apesar da péssima qualidade de suas águas, o rio é um importante, às vezes o único, recurso hídrico para a população que habita nas proximidades e é usado de forma múltipla: para irrigação irrestrita (alface, coentro, couve, repolho, feijão, tomates) e de forrageiras (capim elefante), lavagem de roupas, fabricação de tijolos e recreação de contato primário, evidenciando-se o uso indireto de esgotos.

O uso de águas residuárias é uma prática antiga que vem ganhando importância com a redução da disponibilidade de recursos hídricos de boa qualidade. É uma alternativa importante para irrigação pois, além de permitir o aproveitamento potencial de água e dos nutrientes dos esgotos para o crescimento das plantas, constitui-se, ainda, num método de polimento dos efluentes de estações de tratamento. No entanto, o uso de esgotos ou de águas contaminadas por esgotos na agricultura, deve estar condicionado ao tratamento dos esgotos, a restrições quanto aos tipos de culturas, à escolha de métodos de aplicação e ao controle da exposição dos trabalhadores (Strauss \& Blumenthal, 1989).

Além dos aspectos bacteriológicos, a qualidade da água utilizada na agricultura refere-se também às suas características físicas e químicas. A quantidade de sais é um importante fator a ser analisado. Segundo Ayers \& Westcot (1991) a qualidade da água e/ou sua adequabilidade à irrigação é determinada pela gravidade dos problemas que podem surgir depois do uso em longo prazo. Os problemas mais comuns no solo são relacionados à salinidade, ao efeito sobre a permeabilidade do solo, à toxicidade, ao excesso de nutrientes, aos bicarbonatos e à faixa de $\mathrm{pH}$. Os sais do solo e da água reduzem a disponibilidade de água para as plantas e podem tornar os solos estéreis. Segundo Bernardo (1995) a principal causa da salinização dos solos agrícolas tem sido o manejo inadequado da irrigação (quantidade de água insuficiente ou em excesso e distribuição não uniforme) e a destruição da vegetação nativa.
Ante o uso sistemático das águas do Baixo Rio Bodocongó em várias atividades antrópicas nas áreas das margens, este estudo teve como objetivo analisar a qualidade da água deste rio e sua adequabilidade para os usos atuais como também avaliar a qualidade sanitária do capim e do repolho irrigados.

\section{MATERIAL E MÉTODOS}

Devido à inexistência de mapas em escala detalhada da região, fez-se o levantamento do traçado do Baixo Rio Bodocongó, com o auxílio de um GPS (marca Garmin 45) percorrendo-se, a pé, toda a sua extensão. Foram registrados o uso dessas águas, o número e a localização de bombas de captação de água, as culturas irrigadas ao longo do percurso e o uso dos solos. Este levantamento permitiu escolher-se sete pontos de coleta (PB1 a PB7) ao longo dos $50 \mathrm{~km}$ estudados, para a caracterização física, química e sanitária da água, e de três áreas, para coleta de vegetais e solos (Fig. 2). Os vegetais selecionados foram capim elefante (Pennisetum purpureum) e repolho (Brassica oleracea). O capim por ser largamente cultivado nas margens do rio, e serve como um referencial de contaminação de cultura destinada à alimentação animal, e o repolho à alimentação humana, porque pode ser ingerido cru.

Realizaram-se seis campanhas de campo para coleta de água, entre março e junho de 1999, as quais incluíram a coleta de amostras e medições de vazão, e três campanhas de coleta de solos e vegetais, em junho, setembro e outubro do mesmo ano. As amostras de água foram coletadas em um ponto central de cada uma das sete seções demarcadas no rio, enquanto as de solo foram coletadas em oito pontos de cada área, para se preparar duas amostras compostas do solo irrigado e, em uma área próxima não irrigada, coletava-se a amostra controle para comparação dos resultados. Para coleta das amostras destinadas a análises microbiológicas, utilizaram-se amostradores tubulares de ferro galvanizado previamente esterilizados, de $5 \mathrm{~cm}$ de diâmetro por $20 \mathrm{~cm}$ de altura, que foram enterrados no solo e seu conteúdo acondicionado em sacos plásticos estéreis.

Em cada área foram coletadas duas amostras de capim e repolho irrigados por métodos superficiais, retiradas em seis pontos eqüidistantes da área cultivada, evitando-se as bordas. Os vegetais foram acondicionados em sacos plásticos estéreis e as amostras para análises microbiológicas foram transportadas para o laboratório em caixas de isopor com gelo e processadas em um prazo máximo de $8 \mathrm{~h}$ após a coleta.

Para a análise dos parâmetros físico-químicos $(\mathrm{pH}$, dureza total, condutividade elétrica, alcalinidade de bicarbonatos e de carbonatos, cálcio, magnésio, potássio, sódio e cloretos) utilizaram-se as metodologias descritas em APHA (1995). Nos solos, foram analisados: hidrogênio, alumínio, cálcio, magnésio, sódio e potássio estáveis, $\mathrm{pH}$, carbonato de cálcio e condutividade elétrica do extrato de saturação, de acordo com as metodologias recomendadas pela EMBRAPA (1997).

Os parâmetros microbiológicos analisados foram coliformes fecais (CF), Escherichia coli (E. coli) e ovos de Ascaris lumbricoides. Nas amostras de água para análise de CF utilizou-se a técnica da membrana filtrante - meio $\mathrm{mFC}$ e, para $E$. coli, a técnica NMP, usando-se cartelas e o substrato cromogênico MUG (APHA, 1995). Nas amostras de solo e vegetais, usou-se a técnica dos tubos múltiplos (APHA, 1995), utilizando-se na fase presuntiva o caldo lactosado (Oxoid) e, na confirmativa, o 
Tabela 1.Valores médios (M), mínimos e máximos (F) dos parâmetros* relativos à salinidade da água do Baixo Rio Bodocongó, PB, entre março e junho de 1999

\begin{tabular}{|c|c|c|c|c|c|c|c|c|c|c|c|c|}
\hline \multirow{2}{*}{\multicolumn{2}{|c|}{ Local }} & \multicolumn{4}{|c|}{ Cátions (mg L $\left.{ }^{-1}\right)$} & \multicolumn{3}{|c|}{ Ânions $\left(\mathrm{mg} \mathrm{L}^{-1}\right)$} & \multirow{2}{*}{$\mathrm{pH}$} & \multirow{2}{*}{$\begin{array}{c}\mathrm{DT} \\
\left(\mathrm{mg} \mathrm{L}^{-1}\right)\end{array}$} & \multirow{2}{*}{$\begin{array}{c}\operatorname{RAS}^{\mathrm{o}} \\
\left(\mathrm{mmol} \mathrm{L}^{-1}\right)^{0,5}\end{array}$} & \multirow{2}{*}{ 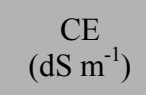 } \\
\hline & & $\mathrm{Ca}^{2+}$ & $\mathrm{Mg}^{2+}$ & $\mathrm{Na}^{+}$ & $\mathrm{K}^{+}$ & $\mathrm{HCO}_{3}^{-}$ & $\mathrm{SO}_{4}^{2-}$ & $\mathrm{Cl}^{-}$ & & & & \\
\hline \multirow{2}{*}{ PB1 } & $\mathrm{M}$ & 73 & 70 & 339 & 40 & 515 & 43 & 532 & 7,5 & 373 & \multirow{2}{*}{7,8} & 2,42 \\
\hline & $\mathrm{F}$ & $44-96$ & $54-96$ & $237-402$ & $35-50$ & $373-612$ & $31-78$ & $402-586$ & $7,2-7,9$ & $241-506$ & & $2,13-3,09$ \\
\hline \multirow{2}{*}{ PB2 } & M & 78 & 71 & 424 & 43 & 485 & 50 & 555 & 7,5 & 442 & \multirow{2}{*}{9,7} & 2,39 \\
\hline & $\mathrm{F}$ & $46-90$ & $54-88$ & $337-579$ & $38-52$ & $358-606$ & $31-83$ & $449-602$ & $6,8-7,9$ & $363-517$ & & $2,22-2,71$ \\
\hline \multirow{2}{*}{ PB3 } & M & 79 & 74 & 456 & 43 & 446 & 61 & 566 & 7,7 & 456 & \multirow{2}{*}{10,2} & 2,45 \\
\hline & $\mathrm{F}$ & $57-93$ & $56-93$ & $321-618$ & $36-56$ & $322-520$ & $41-94$ & $515-622$ & $7,2-8,1$ & $365-575$ & & $1,97-2,79$ \\
\hline \multirow{2}{*}{ PB4 } & $\mathrm{M}$ & 79 & 102 & 479 & 38 & 426 & 72 & 698 & 7,7 & 565 & \multirow{2}{*}{9,3} & 2,86 \\
\hline & $\mathrm{F}$ & $42-101$ & $75-126$ & $361-699$ & $29-45$ & $344-486$ & $47-111$ & $558-813$ & $7,3-8,2$ & $515-678$ & & $2,34-3,22$ \\
\hline \multirow{2}{*}{ PB5 } & $\mathrm{M}$ & 90 & 118 & 506 & 40 & 372 & 77 & 779 & 7,8 & 617 & \multirow{2}{*}{9,1} & 3,11 \\
\hline & $\mathrm{F}$ & $48-131$ & $76-147$ & $361-755$ & $25-50$ & $312-432$ & $46-117$ & $615-955$ & $7,3-8,5$ & $506-897$ & & $2,47-3,65$ \\
\hline \multirow{2}{*}{ PB6 } & M & 100 & 130 & 533 & 45 & 379 & 84 & 894 & 8,1 & 701 & \multirow{2}{*}{9,2} & 3,39 \\
\hline & $\mathrm{F}$ & $53-133$ & $90-166$ & $321-657$ & $34-52$ & $342-408$ & $48-131$ & $685-1.080$ & $7,5-8,8$ & $540-931$ & & $2,56-4,18$ \\
\hline \multirow{2}{*}{ PB7 } & M & 84 & 151 & 549 & 38 & 382 & 88 & 936 & 8,3 & 733 & \multirow{2}{*}{8,9} & 3,51 \\
\hline & $\mathrm{F}$ & $40-135$ & $93-214$ & $352-866$ & $21-52$ & $312-432$ & $51-135$ & $817-1.157$ & $8,0-8,5$ & $598-1.000$ & & $2,70-4,40$ \\
\hline
\end{tabular}

${ }^{*} \mathrm{Ca}^{2+}$ - Cálcio; $\mathrm{Mg}^{2+}-$ Magnésio; $\mathrm{Na}^{+}-$Sódio; $\mathrm{K}^{+}-$Potássio; $\mathrm{HCO}_{3}{ }^{-}-$Bicarbonato; $\mathrm{SO}_{4}{ }^{2-}$ - Sulfatos; $\mathrm{Cl}^{-}$- Cloreto; DT - Dureza Total em termos de CaCO 3 ; $\mathrm{RAS}^{\circ}$ - Razão de Adsorsão de Sódio Corrigida $\left.\left[\mathrm{RAS}^{\circ}=\mathrm{Na} /\left(\mathrm{Ca}^{0}+\mathrm{Mg}\right) / 2\right)^{0,5}\right]$ em que $\mathrm{Ca}^{0}$ corresponde a Ca corrigido, calculado a partir de concentrações de $\mathrm{Ca}^{-} \mathrm{HCO}_{3}{ }^{-}$e CE (Ayres \& Westcot, 1991); CE - Condutividade Elétrica

meio EC - MUG (DIFCO). A quantificação de ovos de Ascaris lumbricoides nas amostras de água foi feita com a técnica de sedimentação (WHO, 1989).

\section{RESULTADOS E DISCUSSÃO}

\section{Parâmetros físicos e químicos de água}

Na Tabela 1 têm-se os valores médios, mínimos e máximos das concentrações de cátions e ânions, e outros parâmetros analisados nas amostras de água do Baixo Rio Bodocongó, PB.

Observa-se, na Tabela 1, que todos os parâmetros, exceto o bicarbonato, apresentaram aumento gradual de concentração ao longo do rio, o qual pode ser associado à maior taxa relativa de evaporação, em virtude do fluxo reduzido do rio, e a mineralização da matéria orgânica. O íon bicarbonato não apresentou este comportamento, provavelmente, devido ao aumento do $\mathrm{pH}$ e à sua conseqüente transformação em íon carbonato.

Em corpos d'água poluídos por esgotos domésticos, a condutividade se relaciona com a matéria orgânica de origem alimentar, fecal e dos resíduos em geral que incorporam sais à água (Blundi, 1988). A CE média variou de $2,42 \mathrm{dS} \mathrm{m}^{-1}$ no ponto PB1 a 3,51 dS m ${ }^{-1} \mathrm{em}$ PB7, com máximo de 4,40 no mesmo ponto. Comparando-se esses resultados com os obtidos por Lucena (1998) no mesmo rio para o período entre outubro de 1996 a outubro de 1997, a CE apresentou aumento de 30 a 50\% nesses dois últimos anos, sendo mais significativo no ponto PB7. Ressalta-se que na época de amostragem a região passava por um período de estiagem de quase três anos consecutivos (de 1997 a 1999) com totais pluviométricos abaixo da média histórica da região, sendo que as últimas chuvas intensas ocorreram no mês de março/1999. Nesse contexto e entre outros fatores, o aumento de CE é conseqüência da estiagem e da evaporação a ela associada, assim como a maior concentração dos esgotos de Campina Grande, em particular em 1999, devido ao racionamento de água na cidade.

Um fator complementar que deve ter contribuído para o aumento da concentração de sais ao longo do rio, refere-se ao fato de que, a partir de PB4, os totais pluviométricos foram mais baixos (em torno de $400 \mathrm{~mm}$ ano $^{-1}$ ) que em PB1, PB2 e PB3 (em torno de $700 \mathrm{~mm} \mathrm{ano}^{-1}$ ).
A Figura 1 apresenta a variação da CE por ponto de coleta ao longo do período de amostragem; observa-se aumento no mês de abril/1999, depois das chuvas ocorridas em março, que devem ter causado uma lavagem superficial do solo e dos sais acumulados durante o verão; em seguida, com o aumento da vazão decorrente dessas chuvas, houve redução da CE no mês de maio/1999 e tendência de crescimento a partir do mês de junho/1999, quando a vazão se reduziu. Pode-se notar, também, que as curvas são crescentes na ordem dos pontos coletados e no sentido do estuário, com exceção dos pontos PB2 e PB3, que apresentaram condutividade elétrica semelhante ou abaixo daquela do PB1, o que se deve ao fato de que, nas proximidades do ponto PB2, o rio recebe a contribuição de descargas pontuais diversas, que diluem a concentração dos sais na água .

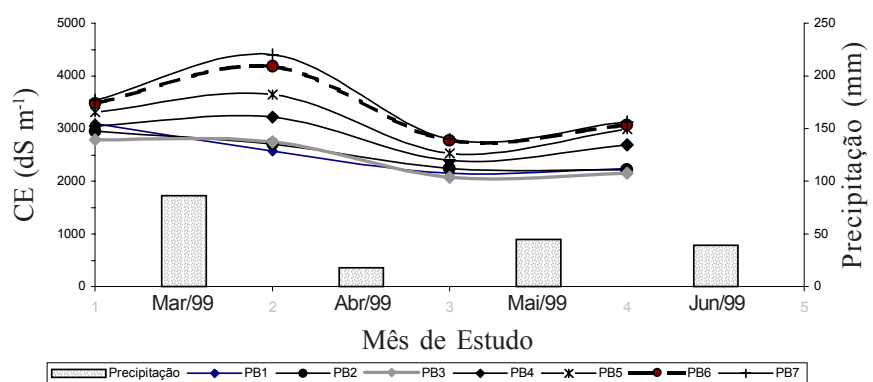

Figura 1. Precipitação mensal na bacia do Baixo Rio Bodocongó, $\mathrm{PB}$, e variação da condutividade elétrica $\mathrm{CE}$ por ponto de coleta ao longo do período de amostragem

Verifica-se na Tabela 1, que as águas contêm predominantemente íons $\mathrm{Na}^{+} \mathrm{e} \mathrm{Cl}-\mathrm{e}$ as variações de $\mathrm{CE}$, dureza total, $\mathrm{Cl}^{-}, \mathrm{Na}^{+}$ e $\mathrm{Mg}^{2+}$ nos diferentes pontos, apresentaram-se com aumento gradativo desde PB1, em Campina Grande, ao ponto PB7, em Barra de Santana, enquanto os outros íons permaneceram quase inalterados ao longo do trecho sob estudo. O íon $\mathrm{HCO}_{3}^{-}$, entretanto, apresentou redução gradual, associada à sua transformação em $\mathrm{CO}_{3}{ }^{2-}$ sob influência do aumento do $\mathrm{pH}$.

Em um estudo realizado em 11 rios do Nordeste brasileiro, nos Estados da Paraíba (Rio Bodocongó), Rio Grande do Norte (Rios Maranguape, Lagoa de Pau, Mossoró, Flexa, Ceará-Mirim 
e Cana Brava), Ceará (Rio Tiasol) e Pernambuco (Rios Juá, Pajeú e Brígida) no período de fevereiro de 1988 a fevereiro de 1990, Audry \& Suassuna (1995) verificaram que a faixa de CE da água estava entre um mínimo de 0,13 e um máximo de $3,90 \mathrm{dS} \mathrm{m}^{-1}$. O Rio Bodocongó apresentou os maiores valores de CE, por estar situado na região mais seca dentre as pesquisadas nesse estudo e, portanto, com maior evaporação e, conseqüentemente, maior concentração de sais.

Os valores médios da dureza total, entre 373 em PB1 e $733 \mathrm{mg} \mathrm{CaCO} \mathrm{L}^{-1} \mathrm{em} \mathrm{PB} 7$ (Tabela 1), tiveram o valor máximo (1.000 mg CaCO $\mathrm{L}_{3}^{-1}$ ) em PB7; este aumento ao longo do rio relaciona-se com as contribuições da bacia de drenagem, na medida em que o rio avança desde suas origens até a foz. A dureza total depende das concentrações de sais bivalentes, principalmente cálcio e magnésio. No Nordeste brasileiro, onde os terrenos são ricos em calcário, as águas têm altas concentrações de ambos os íons, principalmente na forma de bicarbonatos, ocasionando a dureza da água. Sawyer et al. (1994) classificam as águas com valores acima de $300 \mathrm{mg} \mathrm{CaCO}_{3} \mathrm{~L}^{-1}$ como muito duras; portanto, as águas do Baixo Rio Bodocongó apresentaram-se muito duras em todos os pontos estudados. Os valores deste parâmetro constituem mais uma limitação para o uso dessas águas, que não devem ser usadas em processos que envolvam seu aquecimento nem devem permanecer paradas nas tubulações, sob risco de causar incrustações.

Com relação aos principais íons associados à dureza, observa-se na Tabela 1, que as concentrações médias de cálcio variaram entre 73 (em PB1) a $84 \mathrm{mg} \mathrm{L}^{-1}$ (em PB7) com valor máximo de $135 \mathrm{mg} \mathrm{L}^{-1}$ no último ponto. $\mathrm{O}$ aumento da concentração de cálcio ao longo do rio foi inferior ao aumento geral dos sais devido, provavelmente, às altas concentrações dos íons bicarbonatos que podem ter provocado a precipitação do cálcio e magnésio, sob a forma de bicarbonatos e/ou carbonatos. As concentrações médias de magnésio estiveram entre 70 no ponto $\mathrm{PB} 1$ a $151 \mathrm{mg} \mathrm{L}^{-1}$ no $\mathrm{PB} 7$, valores estes acima da faixa considerada normal $\left(0-60 \mathrm{mg} \mathrm{L}^{-1}\right)$ para águas de irrigação, segundo Ayers \& Westcot (1991).

As concentrações de magnésio encontradas por Lucena (1998) entre 35 a $50 \mathrm{mg} \mathrm{L}^{-1}$ no período 1996 - 1997, foram inferiores às do presente trabalho, ou seja, em 2 anos ocorreu aumento de 100 a $200 \%$ deste íon, que pode ser associado à maior concentração dos esgotos e, provavelmente, à maior salinidade da própria água de abastecimento da cidade, pois, o manancial que abastece Campina Grande (Açude Epitácio Pessoa) apresentou redução acentuada do seu volume durante 1997 a 2000 , chegando a atingir apenas $16 \%$ de sua capacidade total em janeiro de 2000 (LMRS, 2000); em conseqüência, teve aumento significativo na concentração dos sais.

A concentração de sódio acompanhou a de outros íons (Tabela 1), aumentando gradualmente ao longo do rio (de 339 no ponto PB1 a $549 \mathrm{mg} \mathrm{L}^{-1}$ no PB7) valores esses bastante altos. De acordo com Laraque (1991) concentrações de sódio acima de $207 \mathrm{mg} \mathrm{L}^{-1}$ na água são problemáticas do ponto de vista da irrigação, por provocarem redução da permeabilidade do solo e pelo seu efeito tóxico nas plantas, podendo causar queimaduras nas folhas e conseqüente queda de rendimento.

Os valores médios de potássio mantiveram-se na faixa de 38 a $40 \mathrm{mg} \mathrm{L}^{-1} \mathrm{em}$ seis pontos (Tabela 1); apenas no ponto PB6 sua concentração subiu para $45 \mathrm{mg} \mathrm{L}^{-1}$, tornando a cair em PB7. Segundo Ayers \& Westcot (1991) concentrações de potássio na faixa de 0 a $78 \mathrm{mg} \mathrm{L}^{-1}$ são normais em águas de irrigação. $\mathrm{O}$ potássio presente nos esgotos domésticos aumenta os teores desse nutriente nas águas superficiais, contribuindo para o processo de eutrofização. Brady (1989) destaca que uma parcela dos solos minerais, com exceção dos arenosos, dispõe de potássio total relativamente elevado mas, via de regra, a quantidade assimilável pelas plantas é pequena. Como este nutriente é essencial para o crescimento dos vegetais, normalmente é necessário aplicá-lo no solo para garantir boas colheitas. A água do Baixo Rio Bodocongó, quando usada para irrigação, pode contribuir para aumentar os teores de potássio no solo.

As concentrações médias de cloretos aumentaram de 532 no ponto PB1 para $935 \mathrm{mg} \mathrm{L}^{-1} \mathrm{em} \mathrm{PB7,} \mathrm{cujas} \mathrm{maiores}$ concentrações ocorreram durante aquelas campanhas, quando a vazão foi menor, devido à maior concentração dos esgotos. Lucena (1998) encontrou, no período de estiagem entre $1996 \mathrm{e}$ 1997, valores médios de 324 em PB1 e $516 \mathrm{mg} \mathrm{L}^{-1}$ no PB7, ou seja, nos dois anos transcorridos entre as duas pesquisas houve incremento de cerca de $80 \%$ na concentração de cloretos. Segundo Lima (1997) valores de cloreto acima de $350 \mathrm{mg} \mathrm{L}^{-1}$ na água de irrigação, causam problemas severos nas plantas. Os sintomas decorrentes do excesso desse íon são queimaduras do ápice das folhas, dentre outros. Caso a irrigação fosse por aspersão, poder-se-ia induzir danos maiores; portanto, o gotejamento é o método mais indicado para se irrigar com águas contendo altos teores de cloreto.

\section{Adequabilidade da água para irrigação}

De acordo com a classificação proposta por Ayers \& Westcot (1991) quanto à salinidade, as águas do Baixo Rio Bodocongó apresentaram grau moderado de restrição (CE de 0,70 a 3,00 dS m$~^{-1}$ ) do ponto PB1 ao PB4 e a partir do PB5 até $\mathrm{PB} 7, \mathrm{o}$ grau de restrição foi severo $\left(\mathrm{CE}>3,00 \mathrm{dS} \mathrm{m}^{-1}\right)$. Essas águas não devem ser usadas em solos com drenagem deficiente e podem ser utilizadas apenas na irrigação de espécies vegetais de alta tolerância à salinidade. Os riscos, por sua vez, podem ser amenizados com a utilização do sistema de irrigação localizada, mantendo teor adequado de umidade no solo. As limitações para utilização das águas do Baixo Rio Bodocongó, quanto à drenagem dos solos e seleção de culturas, se intensificam a partir do ponto PB5. Quanto aos problemas de infiltração, as águas do trecho PB1 a PB7 não apresentaram restrição de uso, porque o $\mathrm{RAS}^{\circ}$ se situou entre 6 e $10\left(\mathrm{mmol} \mathrm{L}^{-1}\right)^{0,5}$ e a condutividade elétrica foi maior que $1,90 \mathrm{dS} \mathrm{m}^{-1}$. Os valores de $\mathrm{pH}(7,4$ a 8,1) estiveram na faixa considerada adequada para água de irrigação. Quanto à toxidade ao sódio, a restrição varia desde moderada até alta, significando que não devem ser utilizadas nas culturas sensíveis como o abacateiro, feijão, milho, laranjeira etc., sobretudo em solos com alto teor de argila (Ayers $\&$ Westcot, 1991; Lima, 1997). Quanto à toxidade dos cloretos, a restrição é severa $\left(\mathrm{Cl}^{-}>355 \mathrm{mg} \mathrm{L}^{-1}\right)$ devendo então ser usadas culturas muito tolerantes. Algumas culturas que toleram bem concentrações de cloreto e sódio semelhantes àquelas das águas do Baixo Rio Bodocongó, são: algodão, beterraba açucareira, couve-flor e girassol (Ayers \& Westcot, 1991). 


\section{Parâmetros microbiológicos}

Na Tabela 2 estão resumidos os valores médios, mínimos e máximos dos parâmetros microbiológicos encontrados nas águas do Baixo Rio Bodocongó.

Ao longo do rio observaram-se elevadas concentrações de $\mathrm{CF}$, com os valores médios mais altos $\left(2,7 \times 10^{6} \mathrm{UFC} 100 \mathrm{~mL}^{-1}\right)$ no ponto $\mathrm{PB} 1$, o qual também apresentou a concentração máxima de $1,4 \times 10^{7}$ UFC $100 \mathrm{~mL}^{-1}$. Valores desta ordem $\left(10^{7} \mathrm{UFC} 100 \mathrm{~mL}^{-1}\right)$ são típicos dos esgotos brutos da cidade de Campina Grande e se associam à presença de bactérias enteropatogênicas, como Salmonella e Listéria e enteroparasitos, como Ascaris lumbricopides, presentes nos esgotos descarregados pela ETE (Ceballos et al., 1997; Moraes et al., 2000 e Soares et al., 2000) enquanto os menores valores $\left(1,0 \times 10^{2} \mathrm{UFC} 100 \mathrm{~mL}^{-1}\right)$ ocorreram nos pontos extremos PB5 e PB7. Analisando-se a distribuição espaço-temporal dos valores de CF, observa-se claro decréscimo ao longo do rio, com decaimento mais acentuado após os primeiros $23 \mathrm{~km}$ (a partir do ponto PB3) quando o rio se torna mais largo e de menor correnteza. Os decréscimos de coliformes fecais e Escherichia coli, estão associados aos fenômenos naturais do processo de autodepuração, onde ocorre remoção e/ ou eliminação das bactérias indicadoras de contaminação fecal e, em conseqüência, de algumas enteropatogênicas, em função dos processos físicos, químicos e biológicos associados à autodepuração, dentre os quais se destacam a sedimentação, a competição, a ação lítica de bacteriófagos específicos e o efeito sinérgico da radiação solar junto aos elevados valores de $\mathrm{pH}$ e de oxigênio dissolvido (Kapuscinski \& Mitchell, 1981, Curtis et al., 1992). Também pode ter havido liberação de substâncias tóxicas na decomposição da matéria orgânica, principalmente provenientes de algumas espécies de algas potencialmente toxigênicas presentes nessas águas. Nunes et al., (2000) estudando a autodepuração nesse rio, observaram que o maior decaimento de coliformes fecais $(99,99 \%)$ ocorria nos últimos pontos, mais rasos e de menor correnteza, com abundante desenvolvimento de algas, influenciando também o tempo de percurso e a menor velocidade da água, que favoreceram a sedimentação.
Comparando-se esses resultados com os de dois anos antes (Mayer et al., 1998) entre 1996 e 1997, a concentração média de coliformes fecais nos primeiros pontos do Baixo Bodocongó era de 4,4 x $10^{6}$ UFC $100 \mathrm{~mL}^{-1}$, significando que ao longo de dois anos ocorreu aumento da contaminação fecal média, de cerca de $30 \%$. Valores médios semelhantes a esses $\left(1 \times 10^{6} \mathrm{UFC} 100 \mathrm{~mL}^{-1}\right)$ foram detectados por Ceballos et al. (1995) em trabalhos pioneiros neste rio, na época de estiagem, enquanto valores de $1 \times 10^{7}$ UFC $100 \mathrm{~mL}^{-1}$ somente foram encontrados na época de chuvas, pela contribuição maior dos esgotos e da bacia de drenagem. O aumento observado no presente trabalho foi independente da época seca ou chuvosa; na verdade, quase não choveu e o ano de 1999 se caracterizou pela estiagem prolongada. Dentre outras causas, como colapso do sistema de tratamento de ETE, o aumento está relacionado ao racionamento de água na cidade de Campina Grande, que reduziu em até $58 \%$ a oferta de água de abastecimento, a partir de 13/10/1998, e se prolongou além do período desta pesquisa. De fato, a redução no consumo de água provocou aumento na concentração dos esgotos e sua vazão, na saída da ETE caiu de $330 \mathrm{~L} \mathrm{~s}^{-1}$ para aproximadamente $80 \mathrm{~L} \mathrm{~s}^{-1}$, de acordo com as medições realizadas nesta pesquisa.

\section{Classificação da água quanto aos riscos sanitários}

De acordo com as recomendações da OMS (WHO, 1989) para irrigação irrestrita, a concentração de coliformes fecais deve ser menor que 1000 UFC $100 \mathrm{~mL}^{-1}$ e de ovos de helmintos deve ser inferior a 1 ovo $\mathrm{L}^{-1}$. Nos pontos PB4, PB6 e PB7 a concentração de coliformes fecais foi inferior ao limite citado, porém nesses pontos a concentração de ovos de Ascaris lumbricoides foi superior. Portanto, nenhum dos pontos atende aos dois critérios, simultaneamente. Esta água só poderia ser usada para irrigar culturas forrageiras e de cereais e os trabalhadores teriam que trabalhar protegidos com roupas e calçados apropriados, para evitar contaminação.

\section{Principais impactos do uso de água}

$\mathrm{Na}$ Tabela 3 são apresentados os valores médios dos parâmetros químicos analisados nos solos irrigados e não irrigados, nas três áreas amostradas.

Tabela 2. Valores médios, mínimos e máximos da concentração de coliformes fecais, Escherichia coli e Ascaris lumbricoides, nas águas do Baixo Rio Bodocongó, PB, entre março e setembro de 1999

\begin{tabular}{|c|c|c|c|c|c|c|c|}
\hline \multirow{2}{*}{ Parâmetro* } & \multicolumn{7}{|c|}{ Local de Coleta } \\
\hline & PB1 & PB2 & PB3 & PB4 & PB5 & PB6 & PB7 \\
\hline \multicolumn{8}{|c|}{ Coliformes Fecais - UFC $100 \mathrm{~mL}^{-1}$} \\
\hline Máximo & $1,4 \times 10^{7}$ & $1,1 \times 10^{7}$ & $2,5 \times 10^{5}$ & $2,2 \times 10^{4}$ & $3,0 \times 10^{4}$ & $4,0 \times 10^{4}$ & $1,0 \times 10^{2}$ \\
\hline Mínimo & $2,2 \times 10^{5}$ & $3,3 \times 10^{4}$ & $4,0 \times 10^{2}$ & $3,0 \times 10^{2}$ & $1,0 \times 10^{2}$ & $1,0 \times 10^{2}$ & $1,0 \times 102$ \\
\hline $\mathrm{N}$ & 7 & 7 & 5 & 3 & 3 & 3 & 1 \\
\hline Máximo & $1,4 \times 10^{7}$ & $5,4 \times 10^{6}$ & $1,0 \times 10^{5}$ & $2,2 \times 10^{4}$ & $9,6 \times 10^{3}$ & $4,9 \times 10^{2}$ & $1,0 \times 10^{2}$ \\
\hline Mínimo & $2,8 \times 10^{4}$ & $7,1 \times 10^{4}$ & $7,9 \times 10^{1}$ & $1,0 \times 10^{2}$ & $1,0 \times 10^{2}$ & $1,0 \times 10^{2}$ & $1,0 \times 10^{2}$ \\
\hline $\mathrm{N}$ & 6 & 6 & 7 & 7 & 7 & 6 & 5 \\
\hline \multicolumn{8}{|c|}{ Ascaris lumbricoides - ovos $\mathrm{L}^{-1}$} \\
\hline Média & 18 & 1 & 3 & 3 & 0 & 9 & 3 \\
\hline Máximo & 45 & 2 & 15 & 15 & 0 & 45 & 15 \\
\hline
\end{tabular}

\footnotetext{
" UFC: Unidade Formadora de Colônia; NMP: Número Mais Provável; N - Números de dados válidos
} 
Tabela 3. Valores médios dos parâmetros químicos analisados nas águas e nos solos irrigados (I) e não irrigados (NI) e classificação dos solos, de acordo com a salinidade em três áreas da bacia do Baixo Rio Bodocongó, em junho de 1999

\begin{tabular}{|c|c|c|c|c|c|c|c|c|c|}
\hline \multirow{4}{*}{ Parâmetro* } & \multicolumn{3}{|c|}{ Área 1} & \multicolumn{3}{|c|}{ Área 2} & \multicolumn{3}{|c|}{ Área 3} \\
\hline & \multirow{3}{*}{$\begin{array}{c}\text { Água } \\
\mathrm{mmol}_{\mathrm{c}} \mathrm{L}^{-1}\end{array}$} & \multicolumn{2}{|c|}{ Solo } & \multirow{3}{*}{$\begin{array}{c}\text { Água } \\
\mathrm{mmol}_{\mathrm{c}} \mathrm{L}^{-1}\end{array}$} & \multicolumn{2}{|c|}{ Solo } & \multirow{3}{*}{$\begin{array}{c}\text { Água } \\
\mathrm{mmol}_{\mathrm{c}} \mathrm{L}^{-1}\end{array}$} & \multicolumn{2}{|c|}{ Solo } \\
\hline & & I & NI & & I & NI & & I & NI \\
\hline & & \multicolumn{2}{|c|}{$\mathrm{cmol}_{\mathrm{c}} \mathrm{kg}^{-1}$} & & \multicolumn{2}{|c|}{$\mathrm{cmol}_{\mathrm{c}} \mathrm{kg}^{-1}$} & & \multicolumn{2}{|c|}{$\mathrm{cmol}_{\mathrm{c}} \mathrm{kg}^{-1}$} \\
\hline Cálcio & 3,66 & 2,80 & 3,62 & 3,90 & 3,14 & 6,30 & 3,95 & 5,77 & 4,15 \\
\hline Magnésio & 5,79 & 2,42 & 2,60 & 5,81 & 3,28 & 3,48 & 8,40 & 4,63 & 1,88 \\
\hline Sódio & 14,75 & 2,67 & 0,45 & 18,43 & 1,47 & 0,32 & 20,83 & 3,47 & 0,25 \\
\hline Potássio & 1,02 & 0,22 & 0,98 & 1,10 & 0,34 & 0,82 & 0,97 & 0,98 & 0,58 \\
\hline Hidrogênio & - & 0,00 & 0,00 & - & 0,00 & 0,61 & - & 0,00 & 0,00 \\
\hline Alumínio total & - & 0,00 & 0,00 & - & 0,00 & 0,00 & - & 0,00 & 0,00 \\
\hline Total de cátions & - & 8,11 & 7,65 & - & 8,23 & 11,53 & - & 14,85 & 6,86 \\
\hline $\mathrm{CE}_{\mathrm{es}}\left(\mathrm{dS} \mathrm{m}^{-1}\right)$ & 2,42 & 0,70 & 0,27 & 2,39 & 0,43 & 0,21 & 2,86 & 1,02 & 0,20 \\
\hline $\mathrm{pH}$ & 7,43 & 7,75 & 7,04 & 7,40 & 7,00 & 6,86 & 7,62 & 8,10 & 7,83 \\
\hline PST (\%) & - & 32,92 & 5,88 & - & 17,86 & 2,78 & - & 23,37 & 3,64 \\
\hline Classificação do solo & & sódico & normal & & sódico & normal & & sódico & normal \\
\hline
\end{tabular}

* $\mathrm{CE}_{\mathrm{es}}$ - Condutividade elétrica do extrato de saturação do solo; PST - Porcentagem de sódio trocável Classificação proposta por Bohn et al. (1985) apud Queiroz et al. (1997)

Os resultados das análises das amostras de solo apresentados na Tabela 3, permitiram avaliar-se a tendência do comportamento do solo após a irrigação. Salienta-se que, para uma caracterização completa, seriam necessários estudos mais profundos envolvendo caracterização de perfil do solo com profundidades maiores e monitoramento regular. A condutividade elétrica do extrato de saturação $\left(\mathrm{CE}_{\mathrm{es}}\right)$ nos solos irrigados variou de $0,43 \mathrm{dS} \mathrm{cm}^{-1}$ na Área 2, a 1,02 dS cm$~^{-1}$ na Área 3. Em todas as áreas, este parâmetro foi mais elevado no solo irrigado em comparação ao não irrigado, devido ao acréscimo de sais decorrente da irrigação. Observa-se que na Área 3, onde ocorreram os maiores valores, a água do rio também apresentou os maiores valores de condutividade elétrica e restrições severas para irrigação. Pode-se afirmar que nessas áreas não existem sistema de drenagem, nem sistema de controle da lâmina de água aplicada, o que agrava ainda mais os efeitos dessas águas sobre o solo. Observa-se na Tabela 3 que na água há predominância de $\mathrm{Na}^{+}$ e $\mathrm{Mg}^{2+}$ que, após serem adsorvidos no solo, o tornam de baixa permeabilidade aumentando, conseqüentemente, os riscos de salinização/sodificação. Solos com $\mathrm{CE}_{\mathrm{es}}$ acima de $2,0 \mathrm{dS} \mathrm{cm}^{-1}$ já são considerados ligeiramente salinos (Bohn et al., 1985, apud Queiroz et al., 1997); portanto, a Área 3 apresenta maior tendência a se tornar salina.

Os valores de $\mathrm{pH}$ dos solos irrigados nas três áreas de amostragem variaram entre 7,0 e 8,1. Os solos das Áreas 1 e 2 têm alcalinidade fraca (Malavolta,1981) e o solo da Área 3, alcalinidade moderada. De acordo com Malavolta (1981) pH em torno de 6,5 é o mais favorável para a maioria das culturas, mas é possível encontrar-se plantas que se desenvolvem normalmente com $\mathrm{pH}$ entre 4,0 e 8,0; portanto, os valores de $\mathrm{pH}$ dos solos das Áreas 1 e 2 foram adequados e apenas a Área 3, que apresentou $\mathrm{pH} 8,1$, está um pouco acima da faixa ótima.

O estudo comparativo entre solos não irrigados e irrigados mostrou que o $\mathrm{pH}$ dos primeiros foi inferior ao $\mathrm{pH}$ dos solos irrigados, diferença que se deve ao acréscimo de sais, principalmente de sódio, que a água de irrigação do Rio Bodocongó incorporou ao solo, causando o aumento do $\mathrm{pH}$ devido à presença de sódio trocável no complexo. Por outro lado, a concentração de cálcio extraível no solo irrigado foi de $2,8 \mathrm{cmol}_{\mathrm{c}} \mathrm{kg}^{-1}$ na Área $1 \mathrm{e}$ foi aumentando, até atingir $5,77 \mathrm{cmol}_{\mathrm{c}} \mathrm{kg}^{-1}$ na Área 3. Comparando-se as concentrações de cálcio do solo irrigado com as do solo não irrigado nas Áreas 1 e 2, percebe-se que o teor de cálcio no solo não irrigado foi superior ao do solo irrigado; normalmente, o teor de cálcio e o total de cátions extraíveis deveriam ser mais altos no solo irrigado, em razão do aporte de matéria orgânica pela água de irrigação, porém na Área 2 o total de cátions extraíveis do solo não irrigado foi superior ao do solo irrigado. A única explicação plausível é a de que as amostras, apesar de terem sido coletadas em áreas próximas e homogêneas, talvez pertençam a manchas de solos diferentes. Verifica-se que nas Áreas 1 e 3 os cátions totais extraíveis nos solos irrigados foram superiores aos dos solos não irrigados, evidenciando que a água de irrigação aumentou a concentração de cátions no solo; no entanto, na Área 1 o teor de cálcio extraível no solo não irrigado apresentou-se superior ao do solo irrigado decorrente, provavelmente, da substituição do cálcio por sódio. Como a água de irrigação apresenta altos teores de sódio, este tende a substituir outros cátions. Segundo Brady (1989) quando há acúmulo de sais em determinados solos de regiões áridas, é comum predominarem, na solução do solo, os íons de sódio, que poderão igualar, ou mesmo exceder, aqueles do cálcio. Na Área 1, o teor de magnésio também foi mais elevado no solo não irrigado que no solo irrigado, devido à substituição por sódio. Também nos solos irrigados a concentração de magnésio foi crescendo da Área 1 de 2,42 até $4,63 \mathrm{cmol}_{\mathrm{c}} \mathrm{kg}^{-1}$ na Área 3. Os teores de magnésio na água de irrigação também aumentaram de 5,79 na Área 1, para $8,40 \mathrm{cmol}_{\mathrm{c}} \mathrm{kg}^{-1}$ na Área 3; já no solo irrigado da Área 3, este processo não ocorreu e o solo irrigado apresentou teores de magnésio superiores $\left(4,63^{-1} \mathrm{cmol}_{\mathrm{c}} \mathrm{kg}^{-1}\right)$ aos do solo não irrigado $\left(1,88 \mathrm{cmol}_{\mathrm{c}} \mathrm{kg}^{-1}\right)$. De acordo com a classificação de Bohn et al. (1985) apud Queiroz et al. (1997) os solos irrigados apresentam caráter sódico.

Os teores de potássio nos solos irrigados variaram de 0,22 na Área 1 a $0,98 \mathrm{cmol}_{\mathrm{c}} \mathrm{kg}^{-1}$ na Área 3, e seu comportamento foi semelhante ao dos outros cátions.

\section{Parâmetros microbiológicos}

Foram realizadas análises microbiológicas nas amostras das três áreas, nos quais se verificou a existência de culturas para consumo humano, além do cultivo de gramíneas para consumo 
Tabela 4. Valores médios da concentração de coliformes fecais (CF) e de Escherichia coli (E. coli) nas amostras de água e solos no Baixo Rio Bodocongó, PB

\begin{tabular}{|c|c|c|c|c|c|c|}
\hline \multirow[b]{2}{*}{ Área } & \multicolumn{2}{|c|}{ Água } & \multicolumn{2}{|c|}{ Solo Irrigado } & \multicolumn{2}{|c|}{ Solo não Irrigado } \\
\hline & $\begin{array}{c}\mathrm{CF} \\
\text { UFC } 100 \mathrm{~mL}^{-1}\end{array}$ & $\begin{array}{c}\text { E. coli } \\
\text { NMP } 100 \mathrm{~mL}^{-1}\end{array}$ & $\begin{array}{c}\text { CF } \\
\text { NMP g }^{-1}\end{array}$ & $\begin{array}{l}\text { E. coli } \\
\text { NMP g }^{-1}\end{array}$ & $\begin{array}{c}\text { CF } \\
\text { NMP g }{ }^{-1}\end{array}$ & $\begin{array}{l}\text { E. coli } \\
\text { NMP g }^{-1}\end{array}$ \\
\hline 1 & $1,2 \times 10^{6}$ & $3,9 \times 10^{5}$ & $6,5 \times 10^{4}$ & $2,7 \times 10^{4}$ & $2,0 \times 10^{2}$ & 0 \\
\hline 2 & $1,0 \times 10^{5}$ & $2,0 \times 10^{4}$ & $3,3 \times 10^{3}$ & $1,1 \times 10^{3}$ & $2,0 \times 10^{2}$ & 0 \\
\hline 3 & $4,0 \times 10^{3}$ & $1,4 \times 10^{3}$ & $3,3 \times 10^{3}$ & $1,3 \times 10^{3}$ & $4,0 \times 10^{2}$ & 0 \\
\hline
\end{tabular}

UFC - Unidade formadora de colônia; NMP - Número mais provável

animal. A Figura 2 apresenta as concentrações de coliformes fecais na água, nos solos e nas culturas irrigadas nas três áreas amostradas do Baixo Rio Bodocongó, PB, entre junho e outubro de 1999. A Tabela 4 apresenta as variações das concentrações de coliformes fecais e de Escherichia coli nos solos dessas três áreas.

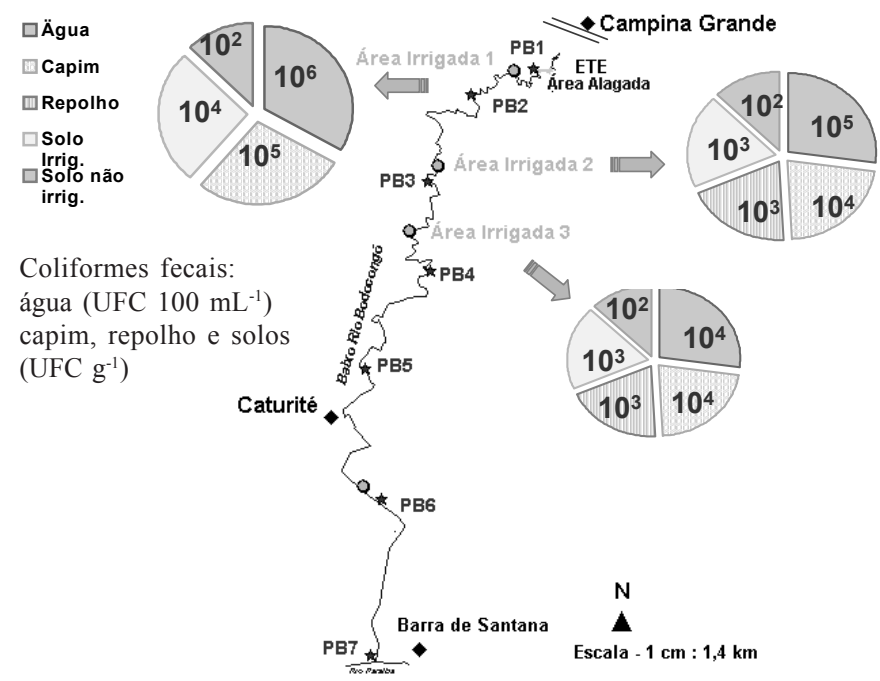

Figura 2. Concentração de coliformes fecais na água, nos solos e nos vegetais irrigados nas margens do Baixo Rio Bodocongó (PB) entre junho e outubro de 1999

Nas amostras de solo irrigado, as concentrações de coliformes fecais foram superiores às dos solos não irrigados, devido à contribuição da água de irrigação e, também, à prática de adubação com esterco animal. Barros et al. (1999) encontraram que em solos com aplicação de estrume, a concentração de coliformes fecais variava de $10^{4} \mathrm{a}_{10} \mathrm{NMP} \mathrm{g}^{-1}$, enquanto em solos sem aplicação de estrume a concentração era de uma a duas unidades logarítmicas inferiores, variando de $10^{2}$ a $10^{4} \mathrm{NMP} \mathrm{g}^{-1}$. O maior problema da irrigação com esgoto doméstico sem tratamento adequado é o risco de contaminação dos produtos irrigados, principalmente daqueles ingeridos crus. Segundo Feachem et al. (1983) ovos de Ascaris lumbricoides, por exemplo, podem sobreviver de 1 a 2 anos no solo úmido e contaminar os produtos irrigados, em particular aqueles muito próximos ao solo, como alface, pepino, repolho, coentro etc.

No capim utilizado como indicador do potencial de contaminação pela água de irrigação, verificou-se que a concentração de coliformes estava abaixo daquela da água, em torno de 1 unidade logarítmica, exceto na Área 3, onde os valores foram muito próximos. Apesar desse valor mais baixo, a concentração remanescente evidencia alto risco de contaminação dos produtos irrigados, ressaltando-se que as amostras de repolho apresentaram contaminação com coliformes fecais da ordem de $10^{3} \mathrm{NMP} \mathrm{g}^{-1}$, com duas unidade logarítmicas abaixo daquela da contaminação da água. Avaliando a qualidade sanitária da alface (Lactuca sativa L.), Barros et al. (1999) encontraram concentrações de coliformes fecais da ordem de $10^{4} \mathrm{NMP} \mathrm{g}^{-1}$, próximas da concentração das águas de irrigação e, às vezes, até superiores, devido à contaminação pelo esterco aplicado ao solo. A contaminação mais baixa das amostras de repolho pode ser decorrente da liberação de substâncias ácidas ou tóxicas às bactérias, pelas folhas da planta, ao serem cortadas para se proceder às análises ou pelo fato deste vegetal apresentar folhas muito fechadas, uma acima da outra, dificultando a penetração da própria água contaminada. Outra provável interferência pode ter sido o agrotóxico utilizado apenas nas plantações de repolho que, segundo informações dos produtores, era aplicado uma vez por semana. Durante as coletas procurou-se colher as amostras nas áreas onde o agrotóxico havia sido aplicado há mais tempo mas, ainda assim, os resíduos podem ter mascarado o resultado das análises; mesmo assim, as concentrações obtidas foram superiores aos valores estabelecidos pela Portaria No 451, de 19/09/1997, da Secretaria de Vigilância Sanitária (SVS, 1997) segundo a qual, para hortaliças frescas, refrigeradas ou congeladas, consumidas cruas (caso do repolho, muito utilizado em saladas cruas) o limite de contaminação por coliformes fecais é de $200 \mathrm{UFC} \mathrm{g}^{-1}$, significando que o repolho das áreas irrigadas por métodos superficiais no Baixo Bodocongó estava com contaminação 17 vezes superior ao permitido pela legislação.

\section{CONCLUSÕES}

1. A qualidade da água do Rio Baixo Bodocongó apresentou forte variação espacial e temporal, que influencia diretamente as condições físicas, químicas e sanitárias dos solos e dos vegetais irrigados.

2. A água do Baixo Rio Bodocongó é imprópria para irrigação irrestrita e em nenhum dos pontos a qualidade da água atende simultaneamente aos dois critérios sanitários da WHO.

3. Solos em áreas irrigadas apresentaram valores de condutividade elétrica e de sódio trocável mais altos que os de áreas não irrigadas.

4. Os vegetais irrigados apresentaram altas concentrações de coliformes fecais, evidenciando o risco da água do rio contaminar os produtos irrigados. $\mathrm{O}$ repolho irrigado apresentou valor até 17 vezes superior ao limite permitido pela legislação vigente, para alimentos ingeridos crus. 


\section{LITERATURA CITADA}

APHA - American Public Heath Association. Standard methods for the examination of water and wastewater. 19 ed. Washington D.C.: APHA-AWWA-WPCF. 1995. 953p.

Audry, P.; Suassuna, J. A salinidade das águas disponíveis para a pequena irrigação no sertão nordestino. Recife, PE: Conselho Nacional de Desenvolvimento Científico e Tecnológico (CNPq). 1995. 127p.

Ayers, R.S.; Westcot, D.W. A qualidade da água na agricultura. Campina Grande: UFPB. 1991.217p.

Barros, A.J.M.; Ceballos, B.S.O.; Konig, A.; Gheyi, H.R. Avaliação sanitária e físico-química das águas para irrigação de hortaliças no agreste e brejo paraibanos. Revista Brasileira de Engenharia Agrícola e Ambiental, Campina Grande, v.3, n.3, p.355-360.1999.

Bernardo, S. Manual de irrigação. 6 ed. Viçosa: UFV. 1995. 657p

Blundi, C.E. Aplicação de métodos alternativos para a determinação de matéria orgânica e biomassa em águas residuárias. São Carlos: Universidade Federal de São Carlos. 1988. 229p. Tese Doutorado

Brady, N.C. Natureza e propriedades dos solos. 7 ed. Rio de Janeiro: Livraria Freitas Bastos. 1989. 898p.

Ceballos, B.S.O.; Konig, A; Gois, S.R. Coliformes fecais, Salmonella spp e Helmintos em lodos de lagoas aeradas. Salerno - Itália. In: Congresso Italo Brasileiro de Engenharia Sanitária e Ambiental, 4, 1997, Salerno. Anais... Salerno, 1997, v.1, p.76-80.

Ceballos, B.S.O.; Lima, E.O.; Konig, A; Martins, M.T. Spatial and temporal distribution of fecal coliforms, coliphages, moulds and yeasts in freshwater at the semi-arid tropic northeast region in Brazil (Paraíba state). Revista Microbiologia, São Paulo, v.3, n.3, p.355-360. 1995.

Curtis, T.P.; Mara, D.D.; Silva, S.A. Influence of pH, oxygen and humic substances on sunlight to damage fecal coliforms in waste stabilization pond water. Applied and Environmental Microbiology, v.58, n.4, p.1335-1343, 1992.

EMBRAPA - Empresa Brasileira de Pesquisa Agropecuária. Manual de métodos de análises de solos. Rio de Janeiro: EMBRAPA. 1997.212p.

Feachem, R.G.; Bradley, D.J.; Garelik, H.; Mara, D.D. Sanitation and disease: Health aspects of excreta and wastewater management. New York: John Wiley \& Sons.1983. 501p.

Kapuscinski, R.B.; Mitchell, R. Solar radiation induces sublethal injury in Escherichia coli in sea water. Applied and Environmental Microbiology, v.41, p.670-674. 1981.

Laraque, A. Comportements hydrochimiques des açudes du Nordeste Brésilien semi-aride. Evolution et prevision pour un usage en irrigation. Montpellier: Université de Montpellier II. 1991.353p. Tese Doutorado

Lima, L.A. Efeito de sais no solo e na planta. In: Gheyi, H.R.; Queiroz, J.E.; Medeiros, J.F. (ed): Manejo e controle da salinidade na agricultura irrigada. Campina Grande: SBEA/ UFPB. 1997. p.113-136.
LMRS - Laboratório de Metereologia, Recursos Hídricos e Sensoriamento Remoto. Dados pluviométricos do Estado da Paraíba e volume do Açude Epitácio Pessoa, PB [online]. Campina Grande, PB. 2000. Várias consultas entre janeiro e fevereiro de 2000. Disponível em http://www.lmrs.pb.gov.br

Lucena, J.H. Estudo da variação espaço temporal da qualidade das águas, de um trecho do Rio Bodocongó, PB. Campina Grande: UFPB. 1998. 116p. Dissertação Mestrado

Malavolta, E. Manual de química agrícola: Adubos e adubação. 3. ed. São Paulo: Editora Agronômica Ceres. 1981. 596p.

Mayer, M.G.R.; Ceballos, B.S.O.; Lucena, J.H.; Konig, A; Suassuna, E.N. Variação espaço-temporal da qualidade das águas de um rio poluído por esgotos domésticos ( $\mathrm{PB}, \mathrm{Brasil})$. In: Congreso Interamericano de Ingenieria Sanitária y Ambiental, 26, 1998, Lima. Anais... Lima, 1998. CDRom

Morais, M.R.; Catão, R.M.R.; Feijó, V.S.G.; Pascoal, S.A.; Ceballos, B.S.O. Comportamento de Salmonella spp, Coliformes fecais e Estreptococos fecais num rio poluído com esgotos (Campina Grande, Paraíba, Brasil). In: Encontro Nacional de Microbiologia Ambiental, 7, 2000, Recife. Resumos... Recife: SBM, 2000, p.76.

Nunes, A.B.A.; Magalhães, N.F.; Pereira, C.B.; Ceballos, B.S.O.; Teixeira, E.C.; Konig, A . Resposta do processo de autodepuração ao impacto dos esgotos domésticos em um rio do semiárido paraibano - Baixo Bodocongó. In: SILUBESA, 9, 2000, Porto Seguro. Anais... Porto Seguro: ABES, v.1,p.37-46, 2000.

PMCG - Prefeitura Municipal de Campina Grande. Plano diretor de águas e solos do município. Campina Grande: Secretaria Municipal de Agricultura. 1995. 320p. Relatório Final

Queiroz, J.E.; Gonçalves, A.C.; Souto; J.S.; Folegatti, M.V. Avaliação e monitoramento da salinidade do solo. In: Gheyi, H.R.; Queiroz, J.E.; Medeiros, J.F. (ed): Manejo e controle da salinidade na agricultura irrigada. Campina Grande: SBEA/ UFPB. 1997. p.69-112.

Richards, L.A. Diagnosis and improvement of saline and sodic soils. Washington, DC: United States Departments of Agriculture, 1954.116p. Handboock 60

Sawyer, C.N.; McCarty, P.L.; Parkin, G.F. Chemistry for environmental engineering. 4. ed. New York: McGraw-Hill Book Company. 1994. 658p.

Soares, N.S.C.; Catão, R.M.R.; Carvalho, W.A.; Ceballos, B.S.O. Freqüência e diversidade de Listeria spp. num rio poluído do trópico semi-árido (Paraíba, Brasil). In: Encontro Nacional de Microbiologia Ambiental, 7, 2000, Recife. Anais... Recife, Sociedade Brasileira de Microbiologia, 2000, p.129.

Strauss, M.; Blumenthal, U.J. Human waste use in agriculture and aquaculture. Duebendorf, Switzerland: IRCWD. 1989.324p.

SVS - Secretária de Vigilância Sanitária. Portaria N. ${ }^{\circ} 451$, de 19 de setembro de 1997. Brasília: Ministério da Saúde. Serviço Público Federal. 1997.

Tundisi, J.G. Limnologia no Século XXI: Perspectivas e desafios. Conferência de abertura do Congresso Brasileiro de Limnologia, 7. São Carlos, SP. 1999. 24p.

WHO - World Health Organization Health guidelines for the use of wastewater in agriculture and aquaculture. Geneva: WHO. 1989. 778p. Technical Report Series 